\title{
Retrospective study of massive obstetric haemorrhage and its materno fetal outcomes in a tertiary care centre
}

\author{
Anju Padmasekar*, Shyamala Jothy
}

Department of Obstetrics and Gynecology, Thanjavur Medical College, Thanjavur, Tamilnadu, India

Received: 21 November 2016

Accepted: 13 December 2016

\author{
*Correspondence: \\ Dr. Anju Padmasekar, \\ E-mail: anjupadmasekar@yahoo.com
}

Copyright: (c) the author(s), publisher and licensee Medip Academy. This is an open-access article distributed under the terms of the Creative Commons Attribution Non-Commercial License, which permits unrestricted non-commercial use, distribution, and reproduction in any medium, provided the original work is properly cited.

\begin{abstract}
Background: Massive obstetric haemorrhage is defined as blood loss of $>1500 \mathrm{ml}$, or a decrease in haemoglobin $>4$ $\mathrm{gm} / \mathrm{dl}$ or acute transfusion requirement of $>4$ units of blood when need for further transfusion is foreseeable. The purpose of this study is to analyse the demographic, medical and obstetric risk factors for massive obstetric haemorrhage and it's materno fetal outcomes.

Methods: Criteria for patient selection was all patients who had an acute obstetric haemorrhage necessitating a transfusion of $>4$ units of blood at a stretch when there was a need for more. This is a retrospective study conducted for a period of one year January to December 2015. Data regarding all cases under study during this period was obtained from Medical Records Department with prior permission. This study was conducted in the Department of Obstetrics and Gynecology, Government Raja Mirasudhar Teaching Hospital, Thanjavur Medical College, Tamil Nadu. Maternal outcomes like mode of delivery, rate of hysterectomy, postpartum complications, maternal mortality and fetal outcomes like intra uterine death, still birth and preterm birth were analysed.

Results: The rate of massive obstetric haemorrhage in our hospital during the study period was 5.7/1000 births. Massive obstetric haemorrhage contributed to $25 \%$ of all maternal deaths in 2015. Atonic PPH was the commonest cause. Multiparity and previous caesarean section were identified to be significant risk factors.

Conclusions: We found an increased association of massive obstetric haemorrhage with multiparity, caesarean sections and pre-eclampsia. Atonic PPH was the commonest cause. Massive obstetric haemorrhage had contributed significantly to adverse maternal and perinatal outcomes.
\end{abstract}

Keywords: Atonic PPH, Hysterectomy, Massive obstetric haemorrhage, Placenta previa/accreta

\section{INTRODUCTION}

Massive obstetric haemorrhage is defined as blood loss of $>1500 \mathrm{ml}$, or a decrease in haemoglobin $>4 \mathrm{gm} / \mathrm{dl}$ or acute transfusion requirement of $>4$ units of blood when need for further transfusion is foreseeable. ${ }^{1,2}$ Obstetric haemorrhage is the main cause of maternal deaths worldwide. It emerges as a major cause of severe maternal morbidity in almost all near miss audits in both developed and developing countries according to $\mathrm{RCOG}^{3}$ The reported prevalence of severe obstetric haemorrhage varies among developed countries from $0.16 \%$ in Canada to $8.8 \%$ in Finland. ${ }^{4,5}$ It contributes significantly to maternal morbidity and mortality. The incidence of massive obstetric haemorrhage is estimated to be 3.7 $5 / 1000$ maternities. $^{6}$ Uterine atony producing massive obstetric haemorrhage is the most common contributor of maternal death. ${ }^{7}$ Massive obstetric haemorrhage is associated with significant co-morbidities like DIVC, shock, renal failure, hysterectomy, maternal death and adverse fetal outcomes like IUFD, LBW, prematurity, still births and increased NICU admissions. Risk factors for massive obstetric haemorrhage like caesarean delivery are more common globally and leads to higher blood loss than normal vaginal delivery. ${ }^{8}$ Previous delivery by caesarean section is associated with increased risk of 
abnormal placentation and peripartum hysterectomy. ${ }^{9}$ High parity is a long-known risk factor for uterine atony. The incidence of $\mathrm{PPH}$ was reported to increase from $0.3 \%$ in women of low parity to $1.9 \%$ with parity of 4 or greater and $2.7 \%$ in parity 7 and above. ${ }^{10}$ Pre eclamptic patients are considered vulnerable for obstetric haemorrhage. ${ }^{11}$ The objective of this study is to determine the frequency, causes, risk factors, mode of delivery and other materno-fetal outcomes.

\section{METHODS}

This is a retrospective study of all cases of massive obstetric haemorrhage that occured during a period of 1 year January to December 2015 in the department of Obstetrics and Gynecology, Government Raja Mirasdar Hospital, attached to Thanjavur Medical College, Tamil Nadu. Totally there were 14,231 deliveries during the study period and total number of cases during study period was 82. Those cases of massive obstetric haemorrhage where there was an acute transfusion of $>4$ units of blood when the need for further transfusion was foreseeable were taken for study as per criteria. Data were collected from Medical Records Department with proper permission. Demographic variables like age, parity, obstetric variables like cause, risk factors, maternal morbidity and mortality and perinatal morbidity and mortality were analysed.

\section{RESULTS}

- Rate of massive obstetric haemorrhage.

- Total number of cases during study period- 82 .

- Total deliveries during study period- 14,231.

- Rate of massive obstetric haemorrhage = $82 / 14231 * 1000=5.7 / 1000$ births.

Massive obstetric haemorrhage occurred in $0.05 \%$ of all deliveries in $2015(8 / 14231 * 100)$. The total number of maternal deaths during study period was 31 and massive obstetric haemorrhage has contributed to $25 \%$ of all maternal mortalities in 2015 in our hospital.

Table 1: Age of study population $(n=82)$.

\begin{tabular}{|lll|}
\hline Age group $\mathbf{n = 8 2}$ & $\mathbf{n}$ & $\%$ \\
\hline$<20$ & 1 & 1.2 \\
\hline $20-29$ & 51 & 62.1 \\
\hline$>30$ & 30 & 36.5 \\
\hline
\end{tabular}

The mean age of study population was 28.3 years. V Brace et al in their study identified the mean age of their study population as 30.9 years.

In this study, $35.3 \%$ of patients were second gravida and $40.2 \%$ of patients were multigravida. This may be explained by the fact that multigravida are more prone for uterine atony and hence massive obstetric haemorrhage.
Table 2: Parity-wise distribution $(\mathbf{n}=\mathbf{8 2})$.

\begin{tabular}{|lll|}
\hline Gravida & $\mathbf{n = 8 2}$ & $\%$ \\
\hline Primi & 20 & 24.3 \\
\hline G2 & 29 & 35.3 \\
\hline G3 and $>$ & 33 & 40.2 \\
\hline
\end{tabular}

Table 3: Mode of delivery $(n=75)$.

\begin{tabular}{|lll|}
\hline Mode of delivery & $n=75$ & $\%$ \\
\hline Vaginal & 22 & 29.3 \\
\hline Caesarean & 53 & 64.6 \\
\hline
\end{tabular}

Excluding the 5 cases of ectopic pregnancies (4 tubal and 1 scar pregnancy) and 2 cases of secondary PPH, mode of delivery was studied in the remaining 75 cases. Out of these normal vaginal deliveries was $29.3 \%$ cases and caesarean section was $64.6 \%$ which shows that caesarean section is a very significant risk factor for massive obstetric haemorrhage.

Table 4: Causes of massive obstetric haemorrhage.

\begin{tabular}{|lll|}
\hline Cause & n = 82 & $\%$ \\
\hline PPH & 34 & 41.4 \\
\hline Placenta previa/accreta & 28 & 34 \\
\hline Abruption & 11 & 13 \\
\hline Tubal ectopic & 4 & 4.8 \\
\hline Rupture uterus & 3 & 3.6 \\
\hline Scar pregnancy & 1 & 1.2 \\
\hline Post op internal bleed & 1 & 1.2 \\
\hline
\end{tabular}

As shown in the above table, PPH is studied to be the commonest cause accounting for $41.4 \%$ of cases and atonicity is the commonest cause of PPH studied $(64.7 \%$ of all PPH cases were atonic PPH).

Among the PPH cases studied 22 were atonic, 5 were traumatic, 5 were due to coagulopathy and 2 were secondary PPH. Placenta previa/accreta syndromes were the second most common cause of massive obstetric haemorrhage studied and account for $34 \%$ of all cases of massive obstetric haemorrhage (28 cases).

Table 5: Risk factors.

\begin{tabular}{|lll|}
\hline Risk factor & n & $\%$ \\
\hline Multiparity (3 and>) & 33 & 40.2 \\
\hline Prev. caesarean & 19 & 23.1 \\
\hline Pre-existing anemia & 11 & 13.4 \\
\hline Pre-eclampsia & 11 & 13.4 \\
\hline HELLP syndrome & 3 & 3.6 \\
\hline Polyhydramnios & 2 & 2.4 \\
\hline Prolonged labour & 2 & 2.4 \\
\hline
\end{tabular}

Among the 28 cases, 18 cases had history of previous caesarean section indicating the fact that caesarean section predisposes to placenta previa/acreta and hence the need to reduce the rate of caesarean sections in future. 
Many studies have shown that previous delivery by caesarean section is associated with abnormal placentation, haemorrhage and peripartum hysterectomy. ${ }^{13-15}$

Among the population studied, $40.2 \%$ were multipara (3 and more) and $23.1 \%$ had history of previous caesarean section indicating that these variables are significant risk factors for massive obstetric haemorrhage. Other identifiable risk factors studied include anemia and preeclampsia.

\section{Hysterectomy in massive obstetric haemorrhage}

Massive obstetric haemorrhage itself often leads to DIVC and massive transfusion also leads onto dilutional coagulopathy and aggravates DIVC. Hence massive PRBC transfusion is accompanied by FFP and platelet transfusion in the ratio of $1: 1: 1$.

Table 6: Maternal outcomes.

\begin{tabular}{|lll|}
\hline Outcome & n & $\%$ \\
\hline Disseminated intravascular coagulation & 21 & 25.6 \\
\hline Ventilatory support & 28 & 34.1 \\
\hline Sepsis & 7 & 8.5 \\
\hline Renal failure & 5 & 6 \\
\hline Death & 8 & 9.7 \\
\hline
\end{tabular}

\section{Maternal death}

According to ACOG National Family Health Survey, in India, the single most common cause of maternal mortality is obstetric haemorrhage accounting for $25-35 \%$ of all maternal deaths. ${ }^{17}$ In our study, there were totally 31 maternal deaths for the year 2015. Among these deaths 8 were due to massive obstetric haemorrhage and hence accounted for $25 \%$ of all maternal deaths in our hospital in 2015. Among the 8 cases, 3 were placenta previa, 3 were progressive HELLP and 2 cases were atonic PPH with irreversible shock. The maternal death rate due to massive obstetric haemorrhage in our study is 9.7\%. (Deaths due to $\mathrm{MOH}[8] /$ total maternal deaths in $2015[82] * 100)$.

Table 7: Perinatal outcomes.

\begin{tabular}{|lll|}
\hline Outcome & n & $\%$ \\
\hline Alive term & 35 & 46.6 \\
\cline { 2 - 3 } IUFD & 20 & 26.6 \\
\hline Alive preterm & 8 & 10.6 \\
\hline Still birth & 7 & 9.3 \\
\hline LBW & 5 & 6.6 \\
\hline
\end{tabular}

Among the babies delivered $53.3 \%$ of babies had perinatal problems due to prematurity, LBW or they were still born or died in utero. PNMR is $[20+7] / 14231 * 1000$ $=1.8 / 1000$ births.

\section{DISCUSSION}

Preeclampsia leads to increased perinatal morbidity and in our study, we found the rate of massive obstetric haemorrhage was 5.7/1000 births. Stones et al reported a rate of 3.2/1000 births and $\mathrm{V}$ Brace et al reported a rate of $3.7 / 1000$ births. $^{12,18}$

In this study, the mean age of our study population was 28.3 years. Brace $\mathrm{V}$ et al in their study identified the mean age of their study population as 30.9 years. ${ }^{12}$ Kodla $\mathrm{CS}$ et al in their study identified the mean age of their study population as $25.5 \pm 4.14$ years. ${ }^{19}$

In our study, $75.5 \%$ of cases were multigravida and $40.2 \%$ were gravida 3 and above.Similar findings were studied by Kodla CS et al and Limaye et al. ${ }^{19,20}$

In this study group, the mode of delivery was caesarean section in $64.6 \%$ of cases and NVD was only $29.3 \%$ of cases. Similar results have been obtained by Chandrika $\mathrm{S}$ Kodla et al $(55.6 \% \mathrm{CS}$ and $40.86 \%$ NVD) and Alzirqui $(60 \% \mathrm{CS}) .{ }^{19,21}$ Brace $\mathrm{V}$ et al in their study have noted a $41 \%$ of all cases of major obstetric haemorrhage in their study were delivered by emergency caesarean section and only $29.4 \%$ of study group had NVD, a finding similar to ours. $^{12}$

The most common cause of massive obstetric haemorrhage in our study was PPH contributing to $41.4 \%$ and uterine atony was the commonest cause of PPH. The second most common cause was placenta previa/acreta (34\%) and next was abruption (13\%) Kodla CS et al have also identified uterine atony as the most common cause of obstetric haemorrhage in their study. ${ }^{19}$ In their study, $22.6 \%$ cases were abruption and $16.52 \%$ cases were placenta previa, Al Zirqui et al in their study have also identified atonic PPH as the commonest cause. ${ }^{21}$

The risk factors for massive obstetric haemorrhage identified in our study were multiparity in $40.2 \%$ cases, history of previous delivery by CS in $19 \%$ cases, anemia in $13.4 \%$ cases, pre-eclampsia in $13.4 \%$ and HELLP in $3.6 \%$ cases. Kodla CS et al in their study have identified anemia as the commonest risk factor in $41.73 \%$ cases. ${ }^{19}$ This difference may be due to the fact that most patients were unbooked and presented in bad shape and hence the difficulty in diagnosing pre-existing anemia. Kodla CS et al have identified pre-eclampsia as a risk factor in $25.19 \%$ of cases, previous caesarean in $18.11 \%$ of cases and HELLP in $7.08 \%$ of cases.

The hysterectomy rates in our study was 3.1/1000 births which was a little higher than the rates given by Brace $\mathrm{V}$ et al and Clark et al for the reasons explained earlier. ${ }^{12,16}$ Kodla CS et al identified a hysterectomy rate of $10.31 \%$ which was similar to findings of Drief et al. ${ }^{19,22}$

Regarding maternal outcomes, 25.6\% had DIVC, $8.5 \%$ developed septicaemia and $6 \%$ developed acute renal 
failure. Kodla CS et al reported sepsis in $8.95 \%$ cases and acute renal failure in $8.52 \%$ cases. $^{19}$

In this study among the 82 cases of study group, mortality occurred in 8 cases. $(9.7 \%)$ Kodla CS et al in their study reported a maternal mortality of $21.73 \% .{ }^{19}$ The most common cause was placenta previa with bleeding and irreversible haemorrhagic shock.

The PNMR in our study is $1.8 / 1000$ births. i.e $36 \%$ of study group. Kodla CS et al reported perinatal mortality in $27.82 \%$ cases. ${ }^{19}$ Kamal AA et al and Limaye et al have reported similar rates. ${ }^{20,23}$

\section{CONCLUSION}

Massive obstetric haemorrhage is a major contributor to maternal morbidity and mortality. Reducing the rates of primary caesarean sections will definitely play an important role in reducing rates of massive obstetric haemorrhage in future. Early recognition of patients at risk, high risk specialised antenatal care for such patients with regular and careful follow-up and intensive care in intrapartum and postpartum periods will definitely reduce the maternal morbidity and mortality.

\section{ACKNOWLEDGEMENTS}

Authors would like to gratefully acknowledge and extend his sincere thanks to Dean, Thanjavur Medical College Hospital, Thanjavur, India for giving permission to do the study using institutional facilities and also extend his thanks to all who helped me complete the study. Authors would like to thank all my colleagues who helped me. My co-author Dr. Shyamala Jothy read and approved the final manuscript.

\section{Funding: No funding sources}

Conflict of interest: None declared

Ethical approval: The study was approved by the Institutional Ethics Committee

\section{REFERENCES}

1. Reports on confidential enquiries into maternal deaths in the UK 1997-1999 London RCOG; 2001.

2. Shevell T, Malone FD. Management of obstetric haemorrhage, Semin Perinatal. 2003;27:86-104.

3. RCOG Green Top guidelines No. 52- Prevention and management of PPH; 2009.

4. Baskett TF, Sternadel J. Maternal intensive care and near- miss mortality in obstetrics. Br J Obstet Gynecol. 1998;105:981-4.

5. Zhang WH, Alexander S, Bouvier-colle $\mathrm{MH}$, Macfarlane A. MOMS- B group. Incidence of severe pre-eclampsia, post-partum haemorrhage and sepsis as a surrogate marker for severe maternal morbidity in a European population based study: the MOMS-B Survey. BJOG. 2005;112:89-96.
6. Chandrasekaran E, Arulkumaran S. Obstetric and intrapartum emergencies: a practical guide to management., Cambridge university. Chapter 5Algorithms for Management of Top Five Direct KillersMassive Obstetric Haemorrhage; 2012:33.

7. Data of Al Zirgi, Berg, Chichakli, Zwart. Contributions to maternal death from various causes of obstetrical hemorrhage. Williams Obstetrics $24^{\text {th }}$ ed. 2008:784.

8. Knight M, Callaghan WM, Berg C. Trends in postpartum haemorrhage in high resource countries: a review and recommendations from the International Postpartum Haemorrhage Collaboration Group. BMC Pregnancy and Childbirth. 2009;9:55.

9. Dalveit AK, Tollanes MC, Pihlstrom H, Irgens LM, Cesarean delivery and subsequent pregnancies. Obs Gynecol. 2008;111(6):1327-34.

10. Kerenji BA, Torok T. Perinatal outcome in grand and great grand multiparity. Am J Obstet Gynecol. 1999;181:699.

11. Tab 41.2 Obstetric haemorrhage causes, predisposing factors, vulnerable patients. Williams Obstetrics 24 th ed. 2008:782.

12. Brace V, Kernaghan D, Penney G. Learning from adverse clinical outcomes: major obstetric haemorrhage in Scotland; 2003-05, BJOG. 2007;114:1388-96.

13. Joseph KS, Rouleau J, Kramer MS, Young DC, Liston $\mathrm{RM}$, Baskett TF. Investigation of an increase in postpartum haemorrhage in Canada. BJOG. 2007;114(6):751-9.

14. Knight M, Kurinczuk JJ, Spark P, Brocklehurst P. Cesarean delivery and peripartum hysterectomy. Obstet Gynecol. 2008;111(1):97-105.

15. Daltveit AK, Tollanes MC, Pihlstrom H, Irgens LM. Cesarean delivery and subsequent pregnancies. Obstet Gynecol. 2008;111(6):1327-34.

16. Clark SL, Yeh S, Phelan JP, Bruce S, Paul RH. Emergency hysterectomy for obstetric haemorrhage. Obstet Gynecol. 1984;64:376-80.

17. International Institute For Population Sciences and Macro International and National Family Health Survey -3, 2005-06: India: Deonar, Mumbai, India; IIPS; 2007:1.

18. Stone RW, Paterson CM, Saunders NJ. Risk factor for major obstetric haemorrhage. Eur J Obstetric Gynecol /Reprod Biol. 2002;45:15-8.

19. Kodla CS. A study of prevalence, causes, risk factors and outcome of severe obstetric haemorrhage. J Sci Innovat Res. 2015;4(2):83-7.

20. Limaye HR. Maternal and fetal outcomes in obstetric emergency cases referred from rural areas. J Obstet and Gynae in India. 1982;32:520-9.

21. Al Vangen ZS, Forsen, L, Pederson SB. Prevalence and risk factors for severe obstetric haemorrhage BJOG, Internat J Obstet Gynecol. 2008;115(10):1265-75.

22. Drife J. Management of primary PPH. Br J Obstet Gynecol. 1997;104:275-7.

23. Kamath AA, Jindal MV. Perinatal mortality in Goa Medical College. J Obstet Gyne India. 2001;51:115-7.

Cite this article as: Padmasekar A, Jothy S.

Retrospective study of massive obstetric

haemorrhage and its materno fetal outcomes in a tertiary care centre. Int J Reprod Contracept Obstet Gynecol 2017;6:554-7. 